\title{
MIPv6 PRotocols: A SURVEY AND COMPARATIVE ANALYSIS
}

\author{
K Vasu ${ }^{1}$, Sudipta Mahapatra ${ }^{1}$ and C S Kumar ${ }^{2}$ \\ ${ }^{1}$ Department of E\&ECE, IIT Kharagpur, Kharagpur, West Bengal, India \\ vasukanster@gmail.com sudipta@ece.iitkgp.ernet.in \\ ${ }^{2}$ Department of Mechanical Engineering, IIT Kharagpur, Kharagpur, West \\ Bengal, India \\ kumar@mech.iitkgp.ernet.in
}

\begin{abstract}
As the future generation networks are envisioned to be heterogeneous in nature, seamless mobility in such networks is an important issue. While IETF work groups have standardized various mobility management protocols, such as Mobile IPv6 (MIPv6), Fast Handovers for Mobile IPv6 (Predictive FMIPv6, and Reactive FMIPv6), Hierarchical Mobile IPv6 (HMIPv6), Proxy Mobile IPv6 (PMIPv6) and Fast Handovers for PMIPv6 (Predictive FPMIPv6, and Reactive FPMIPv6), out of which some are host based and some are network based, the decision regarding which protocol suits the future networks is still a research issue. The study of various mobility management protocols in terms handover latency and the number of hops is needed to evaluate these protocols. Even though much study has been done in literature in terms of handover latency, study still needs performance evaluation in terms of average hop delay. In this paper we study various mobility management protocols by applying simple numerical analysis. The study is carried out for performance evaluation of various mobility management protocols in terms of average hop delay, wireless link delay, wired part delay, and binding update and registration delay. In this work, the average hop delay is estimated in terms of total handover latency and total number of hops contributing to each protocol. The study enables us to make a few important observations regarding the performance of these mobility management protocols.
\end{abstract}

\section{KEYWORDS}

MIPv6 Protocols, Total handover delay, Average hop delay, Wireless link delay, Total number of hops, Binding update/registration delay, Wired part delay (delay between AR/MAG).

\section{INTRODUCTION}

Internet Engineering Task Force (IETF) is standardizing various mobility management protocols, such as MIP, MIPv4, MIPv6, FMIPv6, HMIPv6, and PMIPv6. To utilize advantages of IPv6 protocol over IPv4, a lot of effort is directed towards improving the performance of IPv6 based protocols. One such popular MIP protocol is MIPv6 [4], which greatly reduces the handover latency compared to the MIPv4 protocol. Even though it reduces the handover latency, still the delay introduced by this protocol is not acceptable to the real-time applications like VoIP. This has lead to the development of the faster protocols like FMIPv6 [7] and their enhancements.

Sundarapandian et al. (Eds): CoNeCo,WiMo, NLP, CRYPSIS, ICAIT, ICDIP, ITCSE, CS \& IT 07, pp. 73-93, 2012. () CS \& IT-CSCP 2012

DOI : $10.5121 /$ csit.2012.2408 
In [8], authors propose an enhanced fast handover scheme for MIPv6 to reduce handover latency caused by duplicate address detection (DAD) and binding update. In this method, each access router (AR) maintains a Care-of address (CoA) generation table to assign CoA for a mobile node before moving to the new AR. Also, the previous access router (PAR) establishes a binding update of CoA upon getting it. Performance evaluation of handover latency and packet delay is done using a simple analytical model. In [10], authors proposed an efficient fast handover scheme in MIPv6 to reduce the total handover delay of L2, and L3 layers. In this method, movement detection, CoA generation, and the DAD process are executed on the access router instead of on the mobile node. The new CoA will be sent from the access router side to the mobile node. In [15], authors have studied the delay and packet loss performance during vertical handover in heterogeneous wireless networks. In this, authors used the mobile IP for linux (MIPL) based testbed experimentation for both Ethernet to WiFi and WiFi to Ethernet scenarios. It has been shown that when the mobile node moves from one foreign network to another or returns to home network, handoff delay and packet loss are almost unnoticeable. Also, for a multi-homed mobile node $(\mathrm{MN})$, the MIPv6 performs a better vertical handover.

In the last decade IETF has also standardized the hierarchical mobility management protocol (HMIPv6) [14], which leads to performance benefits in heterogeneous wireless networks. To study the performance metrics related to mobility and traffic of various MIPv6 protocols, authors in [9], propose a new analytical evaluation model. Performance metrics like signaling overhead, packet delivery cost, handoff latency and packet loss are analyzed in this work. Numerical results show that Fast handover for HMIPv6 (F-HMIPv6) improves the handover latency and packet loss than other protocols, while HMIPv6 improves the signaling overhead cost and buffer space requirement compared to other protocols.

To deploy the host based protocols like MIPv6, FMIPv6, and HMIPv6, a mobile host needs to have the support of these protocols in their operating system. Also, one of the severe drawbacks of these host based mobility management protocols is that the mobile host needs to be involved in the protocol operations during the handover time, which increases the signaling overhead and handover latency. So, during the year 2007-2008, the network mobility group (NEMO) from IETF standardized the network based mobility management protocol, e.g., PMIPv6 [3]. Current research activity is focused on enhancing the network based mobility management protocols and their study. A comparison between PMIPv6 and FMIPv6 is done in [1-2]. In both of these papers authors have evaluated the performance of the protocols using the simple analytical models and conclude that for faster radio access technologies, FMIPv6 in predictive mode is better than MIPv6 and PMIPv6 is almost similar to reactive based FMIPv6 in terms of handoff interruption time. However for slower radio access technologies, PMIPv6 is better than FMIPv6 in reactive mode.

To reduce the handover latency caused by the standard MIPv6 protocol, authors in [12] propose a mechanism based on the localized routing within a single administrative domain. In this method, a proxy information server (PIS) is updated with neighbor-hood information of mobile access gateways (MAGs) and their complete feature set. The authors simulated the environment by using numerical analysis of delays encountered by the protocol operations. A survey of Network-based Localized Mobility Management (NETLMM) group is in [5], where authors presented a detailed explanation of signaling process and handover latency for both the host based and network based mobility management protocols. During the handover delay time, packet loss is another important parameter to be considered. Authors in [13] propose a new method to reduce the packet loss due to the huge handover delay caused by PMIPv6. In this packet lossless PMIPv6 method, when the 
current MAG sends the deregistration (DeReg) proxy binding update (PBU) message to the local mobility anchor (LMA), the PBU message of the new MAG is included in the DeReg PBU message. As a result, a tunnel is established between the LMA and new MAG before going to the new MAG. So, when the new MAG receives the proxy binding acknowledgement (PBA) message, it starts buffering the packets addressed to the mobile node.

In [11], authors proposed an extension to PMIP for inter domain mobility to continue mobility support in the MN. Numerical analysis shows that this network based approach improves the performance in terms of handover latency and data delivery costs compared to the MIP, HMIP, and hierarchical PMIP (H-PMIP) solutions. To utilize the advantages of both fast handover and route optimization techniques, authors in [16] proposed coordination based fast handover and route optimization method for PMIPv6. Analysis is done to explain the coordinating function in two scenarios. One considers that all of the MAGs of the MN and the correspondent node $(\mathrm{CN})$ belong to the same LMA and the other considers that each MAG belongs to a different LMA.

From the above discussions, it is cleared that as the future generation networks are heterogeneous in nature where the seamless mobility is an important issue, the investigation and analysis of available mobility management protocols is an important work for designing the mobility management protocols in future networks. In this paper, both host based and network based protocols and their faster versions are analyzed and compared in terms of average hop latency, wireless link delay, wired part delay, and binding update/ registration latency using a simple numerical analysis. The results obtained, enable us to make the important observations as follows: faster network and host based mobility management protocols perform the better average hop delay performance in terms of wireless link delay, wired part delay, and binding update/registration delay. Among these protocols, reactive mode of protocols perform better delay performance in terms of wired part delay and binding update/registration delay components compared to the predictive based protocols. Whereas predictive based protocols performs better performance in terms wireless link delay for faster radio access technologies and performs less performance for slower radio access technologies. The rest of the paper is organized as follows: the existing MIPv6 based protocols are explained in Section-2, followed by the numerical analysis results in Section-3, finally, Section-4 concludes this paper.

\section{Mobility Management Protocols}

In this section, some of the mobility management protocols are presented briefly with their signaling flow diagrams, latency and the number of hops. Signaling flow diagrams are shown by considering the signaling overhead during the handover interruption time, which means by excluding the signaling not involved in handover interruption time. The network model of [6] is considered for handover latency analysis of mobility management protocols. The acronyms used are shown in Table 1. In this model, $\mathrm{T}^{\mathrm{X} 1}{ }_{\mathrm{X} 2}$ denotes the delay due to the operation $\mathrm{X} 2$ of protocol $\mathrm{X} 1$ and $\mathrm{N}^{\mathrm{X} 1}{ }_{\mathrm{N} 1-\mathrm{N} 2}$ represents the number of hops between $\mathrm{N} 1$ and $\mathrm{N} 2$ for a protocol $\mathrm{X} 1$. The symbols used to represent different delay variables are explained in Table 2. The total handover delay $\mathrm{D}^{\mathrm{X} 1}{ }_{\mathrm{HO}}$ and the total number of hops $\mathrm{N}^{\mathrm{X} 1}{ }_{\mathrm{HO}}$ during handover time are derived for each protocol X1. The average hop delay for a particular protocol X1 is considered as the ratio of the total handover delay and number of hops during the handover interruption time, this is denoted as [Avg Hop Delay] ${ }_{\text {HO. }}^{\mathrm{XI}}$ 
Table 1. Acronyms

\begin{tabular}{|l|l|}
\hline Acronym & Definition \\
\hline MN & Mobile Node \\
\hline AP & Access Point \\
\hline PAP & Previous Access Point \\
\hline NAP & New Access Point \\
\hline PAR & Previous Access Router \\
\hline NAR & New Access Router \\
\hline HA & Home Agent \\
\hline CN & Correspondent Node \\
\hline MAG & Mobile Access Gateway \\
\hline LMA & Local Mobility Anchor \\
\hline RS & Router Solicitation \\
\hline RA & Router Advertisement \\
\hline NS & Neighbor Solicitation \\
\hline MD & Movement Detection \\
\hline BU & Binding Update \\
\hline BA & Binding Acknowledgement \\
\hline HOTI & Home Test Init \\
\hline HOT & Home Test \\
\hline COTI & Care-of Test Init \\
\hline COT & Care-of Test \\
\hline RR & Return Routability \\
\hline RtSolPr & Router Solicitation for Proxy Advertisement \\
\hline PrRtAdv & Proxy Router Advertisement \\
\hline AC & Address Configuration \\
\hline FBU & Fast Binding Update \\
\hline FBack & Fast Binding Acknowledgement \\
\hline HI & Handover Initiate \\
\hline Hack & Handover Acknowledgement \\
\hline UNA & Unsolicited Neighbor Advertisement \\
\hline PBU & Proxy Binding Update \\
\hline PBA & Proxy Binding Acknowledgement \\
\hline & \\
\hline
\end{tabular}

Table 2. Symbols used for delay variables

\begin{tabular}{|l|l|}
\hline Delay & Simplified notation \\
\hline TAP-AR=TAP-MAG & tra \\
\hline TMN-AP & tmr \\
\hline TAR-MAP=TMAG-LMA & tam \\
\hline TAR-HA=TMAG-HA & tah \\
\hline TAR-CN=TMAG-CN & tac \\
\hline THA-CN & thc \\
\hline TAR-AR=TMAG-MAG & tpn \\
\hline
\end{tabular}




\subsection{MIPv6}

In the IPv6 Internet, if the mobile node is moving away from its home link, it would not be able to maintain the transport and higher-layer connections. MIPv6 [4] provides a transparent service to the transport, and higher layer protocols and applications. Even though a mobile node is away from the home network, it is always addressed using the home address. The home address is an IP address assigned to a mobile node within its home subnet prefix on its home link. While the mobile is away from the home link and attached to the foreign-link, a care-of address is assigned to the mobile node. This is an IP address assigned to the mobile node that has a foreign network prefix. The mobile node sends a binding update request to the home agent router in the home network to make a binding association between the home address and care-of address. Upon accepting a binding update request from the mobile node, the home agent replies with a binding acknowledgement message.

There are two possible modes of communication between the mobile node and the correspondent node. The first mode does not require the binding of the home address and the care-off address; it uses a bi-directional tunneling mechanism to route the traffic to the mobile node. Traffic from the mobile node is tunneled through the foreign link to the home agent (reverse tunnel), and then normally routed from the home network to the correspondent node. The second mode, called route optimization, requires the mobile node to register its current binding at the corresponding node. The packets from the correspondent node can then directly be routed to the mobile node's care-of address. The signaling flow diagram of MIPv6 during handover interruption time is explained in Fig. 1. The total handover delay $\mathrm{D}^{\mathrm{MIPv} 6}{ }_{\mathrm{HO}}$, number of hops $\mathrm{N}^{\mathrm{MIPv} 6}{ }_{\mathrm{HO}}$, and average hop delay [Avg Hop Delay] ${ }_{\text {HO }}^{\mathrm{MIP} 6}$ of MIPv6 are estimated below. 


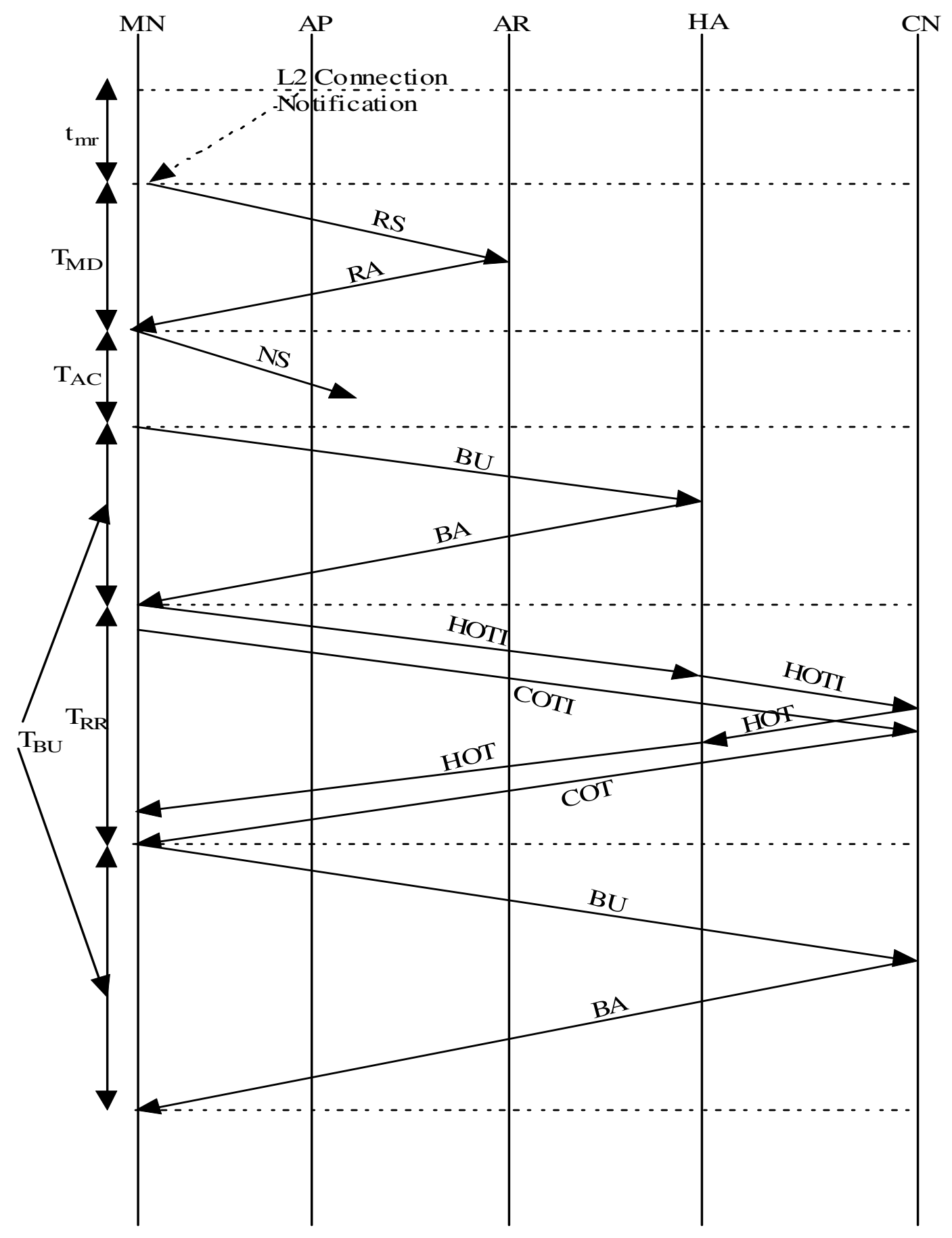

Figure 1. MIPv6 


$$
\begin{aligned}
D_{H O}^{M I P v 6}= & t_{m r}+T_{M D}^{M I P v 6}+T_{A C}^{M I P v 6}+T_{R R}^{M I P v 6}+T_{B U}^{M I P v 6} \\
T_{M D}^{M I P v 6}= & 2 \times\left(t_{m r}+t_{r a}\right) \\
T_{R R}^{M I P v 6}= & 2 \times\left(t_{m r}+t_{r a}+t_{a c}\right) \\
T_{B U}^{M I P v 6}= & 4 \times\left(t_{m r}+t_{r a}\right)+2 \times\left(t_{a h}+t_{a c}\right) \\
N_{H O}^{M I P v 6}= & N_{A P-M N}^{M I P v 6}+2 \times N_{M N-A R}^{M I P v 6}+N_{A C}^{M I P v 6}+ \\
& 2 \times N_{M N-H A}^{M I P v 6}+2 \times N_{M N-C N}^{M I P v 6}+2 \times N_{M N-C N}^{M I P v 6}
\end{aligned}
$$$$
\left[\begin{array}{lll}
A v g & \text { Hop } & \text { Delay }
\end{array}\right]_{H O}^{M I P v 6}=\frac{D_{H O}^{M I P v 6}}{N_{H O}^{M I P v 6}}
$$

\subsection{FMIPv6}

During the handover time, MIPv6 contains the protocol operations like movement detection, IP address configuration, and location update. The handover latency resulting from the standard MIPv6 protocol, which is typically the delay involved due to the link layer switching and IP protocol opearations, is not acceptable for real-time applications. The mobile node may discover available access points and their subnet information using scan procedures before detaching the old access router. To reduce the proxy binding update latency, this protocol [7] specifies a tunnel between the previous $\mathrm{CoA}(\mathrm{PCoA})$ and the new $\mathrm{CoA}(\mathrm{NCoA})$. Setting up a tunnel alone is not sufficient to reduce the delay because the neighbor discovery operation, involving a neighbor address resolution, is rather time consuming. When a link specific event or router discovery occurs, the MN sends a router solicitation for proxy (RtSolPr) message to its access router; in response, the AR sends a router advertisement for proxy (PrRtAdv) message containing the information about access points (APs). From the information obtained by PrRtAdv, the MN formulates the NCoA and sends a fast binding update (FBU) message. Then, a tunnel is formed between the previous access router (PAR) and the new access router (NAR) so that arriving packets can be tunneled to the new location of MN. After submitting the FBU, depending on the receiving mode of fast binding acknowledgement (FBack), there are two modes of operations defined, that is. predictive and, reactive. The signaling flows during the handover interruption time of FMIPv6 for predictive and reactive mode of procedures are presented in Fig. 2 and Fig. 3 respectively.

\subsubsection{Predictive FMIPv6 (FMIPv6 (Pre))}

In this mode of operation, tunneling is made before the mobile node hands over to the new access router by the previous router receiving the fast binding acknowledgement. Before sending FBack to the MN, PAR will authorize the NCoA by exchanging handover initiate (HI), and handover acknowledgement (Hack) messages with the NAR. When assigned addressing is used, the proposed NCoA in the FBU is carried in an HI message (from PAR to NAR), and NAR may assign the proposed NCoA. This assigned NCoA must be returned in Hack (from NAR to PAR), 
and PAR must in turn provide the assigned NCoA in FBack. The MN must use the assigned address after attaching to NAR. MN should also send the unsolicited neighbor advertisement (UNA) immediately after attaching to the NAR, so that arriving as well as buffered packets can be forwarded to the MN as soon as it attaches to the NAR. The total handover delay D ${ }^{\mathrm{FMIPv6(Pre)}}{ }_{\mathrm{HO}}$, number of hops $\mathrm{N}^{\mathrm{FMIPv} 6(\mathrm{Pre})}{ }_{\mathrm{HO}}$, and average hop delay [Avg Hop Delay] ${ }^{\mathrm{FMIPv} \text { (Pre) }}{ }_{\mathrm{HO}}$ of FMIPv6 (Pre) are estimated as given below.

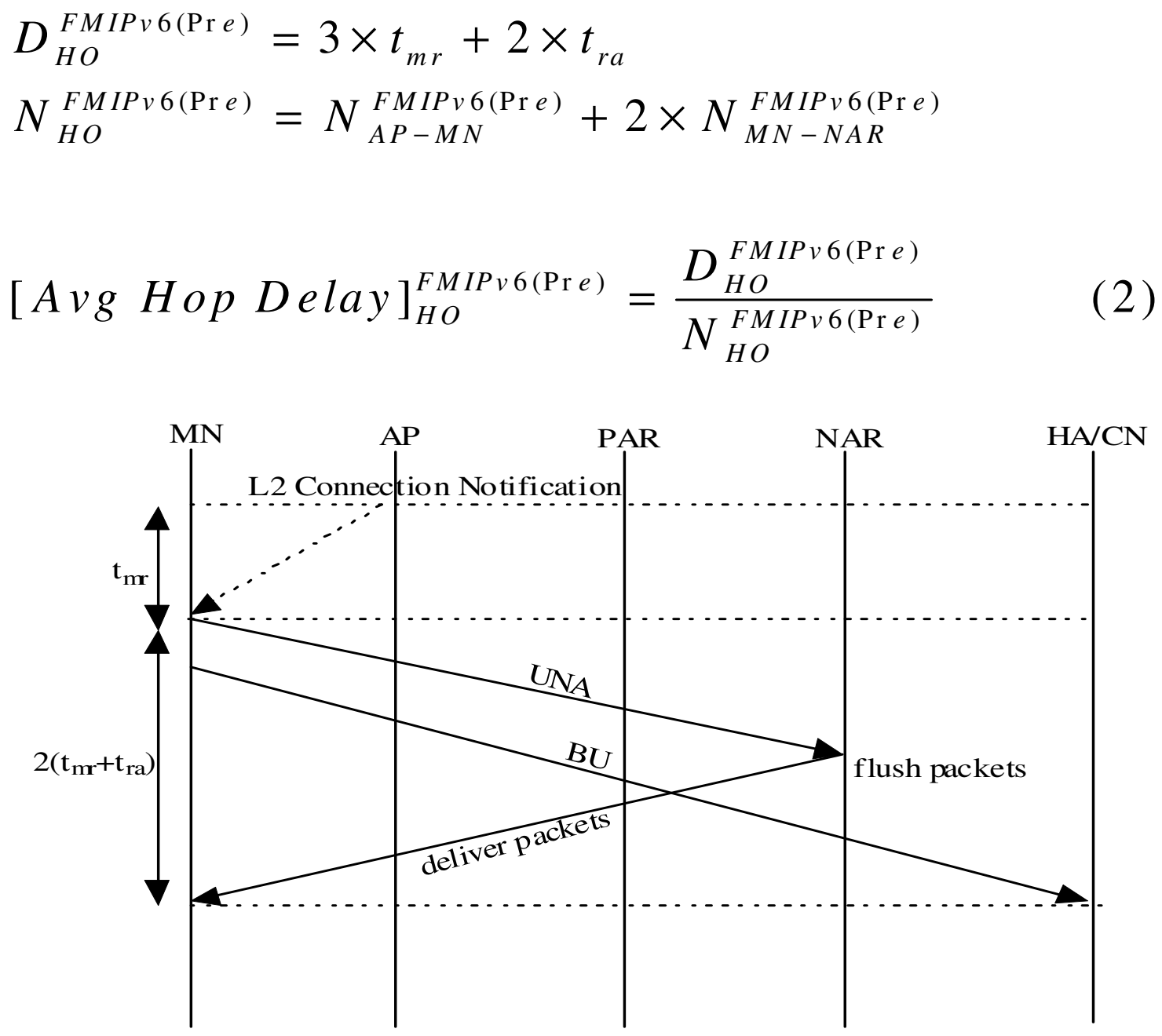

Figure 2. FMIPv6 (Predictive)

\subsubsection{Reactive FMIPv6 (FMIPv6 (Rea))}

In this mode of operation, the $\mathrm{MN}$ does not receive the FBack on the previous link because the $\mathrm{MN}$ has not sent the FBU or the MN has left the link after sending the FBU, but before receiving an FBack. MN re-sends the FBU to the PAR immediately after sending the UNA message due to non guarantee of delivery of the FBU message. If the NAR detects a duplicate address, it may assign an IP address different from the NCoA and it sends a router advertisement with the "Negative Advertisement Acknowledge (NAACK)". The total handover delay $\mathrm{D}^{\mathrm{FMIPv6(Rea)}}{ }_{\mathrm{HO}}$, 
number of hops $\mathrm{N}^{\mathrm{FMIPv6}(\mathrm{Rea})}{ }_{\text {HO, }}$ and average hop delay [Avg Hop Delay] ${ }_{\text {HOIPv6(Rea) }}^{\mathrm{Fo}}$ of FMIPv6 (Rea) are given below.

$$
\begin{aligned}
& D_{H O}^{F M I P v 6(\operatorname{Re} a)}=3 \times t_{m r}+2 \times\left(t_{r a}+t_{p n}\right) \\
& N_{H O}^{F M I P v 6(\operatorname{Re} a)}=N_{A P-M N}^{F M I P v 6(\operatorname{Re} a)}+N_{M N-N A R}^{F M I P v 6(\operatorname{Re} a)}+N_{N A R-P A R}^{F M I P v 6(\mathrm{Re} a)} \\
& +N_{P A R-N A R}^{F M I P v 6(\mathrm{Re} a)}+N_{N A R-M N}^{F M I P v 6(\mathrm{Re} a)}
\end{aligned}
$$

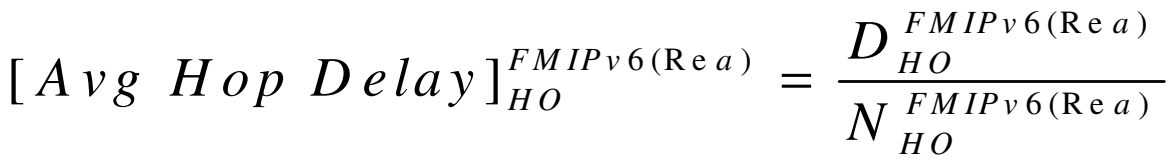

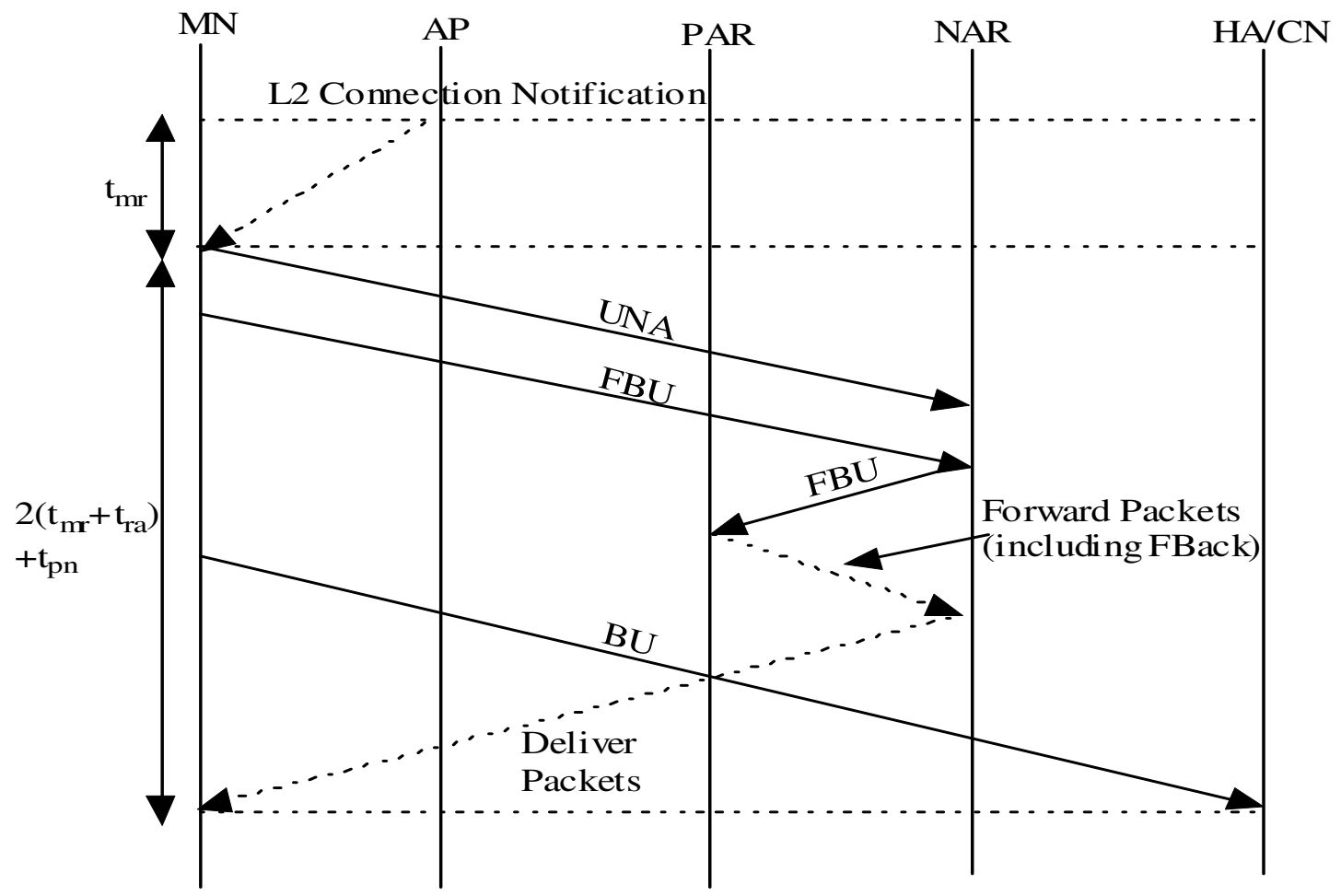

Figure 3. FMIPv6 (Reactive)

\subsection{HMIPv6}

In MobileIPv6, the mobile node sends its binding updates to the HA and all of the correspondent nodes, which ultimately increases the handover delay. Eliminating this delay significantly improves the performance of MIPv6. Moreover, this solution reduces the message overhead imposed on the radio interface. So, HMIPv6 [14] introduces a new MobileIPv6 node, called the 
mobility anchor point (MAP). The mobile node obtains the global address of the MAP from the router advertisements by using MAP discovery procedure. Also the MAP process determines the distance of MAP from the MN. A change in the advertised MAP's address is to be notified to the HA and correspondent nodes by sending binding updates. The mobile node first needs to register with a MAP by sending it a BU containing its Home address and the on-link CoA (LCoA). The Home Address used in the $\mathrm{BU}$ is the regional CoA (RCoA). The MAP forwards the packets to the mobile node by using this binding information. To use the network bandwidth in a more efficient manner, the MN can register with more than one MAP simultaneously and use each MAP address for a specific group of CNs. The signaling flow diagram of HMIPv6 during handover interruption time is explained in Fig. 4. The total handover delay $\mathrm{D}^{\mathrm{HMIPv} 6}{ }_{\mathrm{HO}}$, number of hops $\mathrm{N}^{\mathrm{HMIPv} 6}{ }_{\mathrm{HO}}$, and average hop delay [Avg Hop Delay] ${ }_{\mathrm{HIO}}^{\mathrm{HM} 6}$ of HMIPv6 are given below.

$$
\begin{aligned}
& D_{H O}^{H M I P v 6}=t_{m r}+T_{M D}^{H M I P v 6}+T_{A C}^{H M I P v 6}+T_{B U}^{H M I P v 6} \\
& T_{M D}^{H M I P v 6}=2 \times\left(t_{m r}+t_{r a}\right) \\
& T_{B U}^{H M I P v 6}=2 \times\left(t_{m r}+t_{r a}+t_{a m}\right) \\
& N_{H O}^{H M I P v 6}=N_{A P-M N}^{H M I P v 6}+2 \times N_{M N-A R}^{H M I P v 6}+N_{A C}^{H M I P v 6} \\
& +2 \times N \begin{array}{c}
H M I P v 6 \\
M N-M A P
\end{array}
\end{aligned}
$$

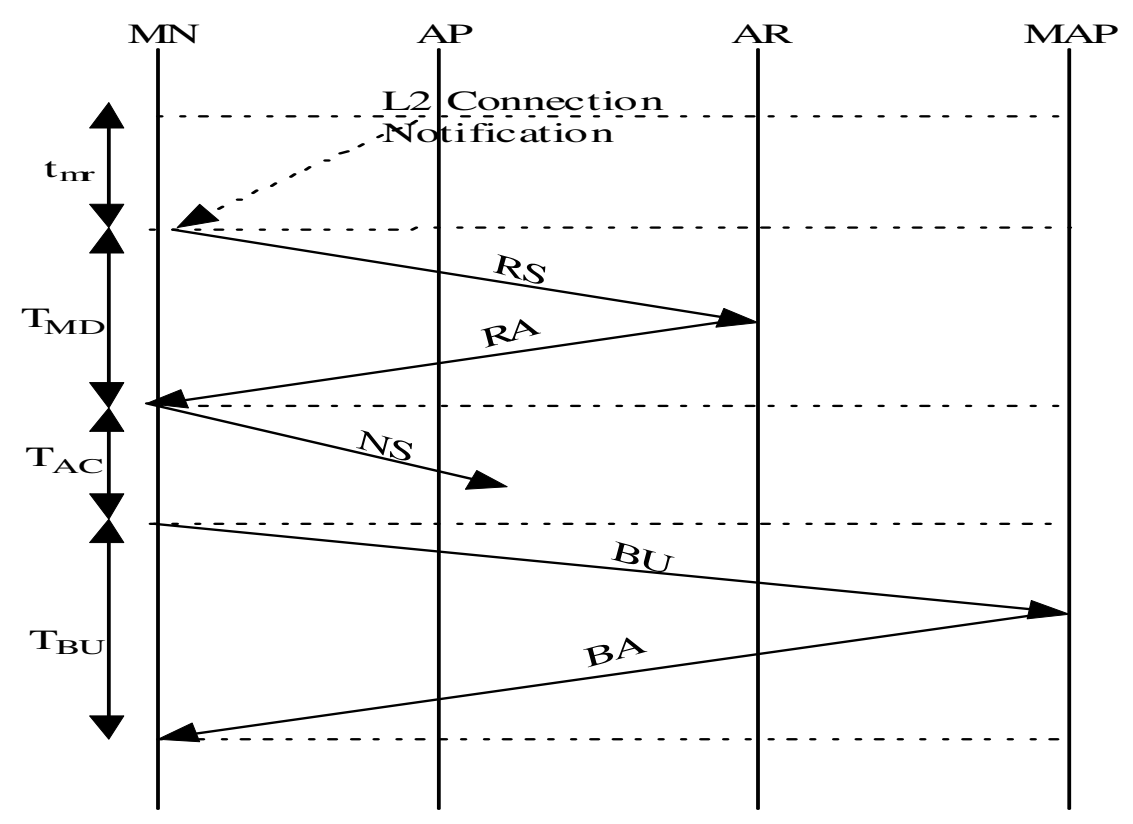

Figure 4. HMIPv6 


\subsection{PMIPv6}

Mobility support in MIPv6 [4] requires the client functionality in IPv6 stack of mobile nodes. In this regard, a lot of signaling messages need to be exchanged between the mobile node and its home agent, and also it is required to maintain the binding information between the home address and the care-off address. Network based mobility is a solution which removes the mobile node involvement in mobility signaling messages and binding update, Instead, proxy agents in networks do the mobility management on behalf of the mobile host. One such solution of network based mobility is the PMIPv6 [3].

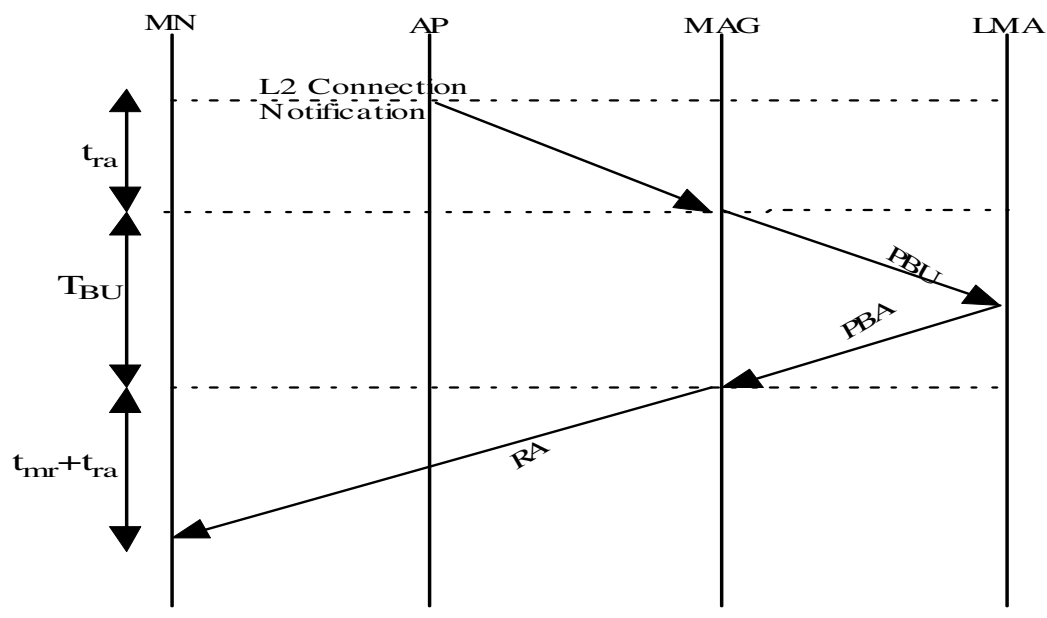

Figure 5. PMIPv6

Two of the key components in PMIPv6 are MAG and LMA. MAG handles all of the mobility related signaling for a mobile node that is attached to the access point, where it is also responsible for keeping track of the movements of the mobile node within the network. The functionality of LMA is similar to that of the home agent in MIPv6. It is responsible for managing the mobile node's binding state. When the mobile node enters the proxy mobile IPv6 domain, the mobile access gateway in that domain identifies the mobile node and determines whether the mobile node is authorized for the service or not [17]. Once the mobile is authorized for network based mobility service, it can obtain home network prefixes, default router address on that access link, and other related configuration parameters by using any of the address configuration mechanisms to move in that proxy mobile IPv6 domain. Once the router solicitation messages comes from the mobile node after attaching to the access link in a specific proxy mobile IPv6 domain, the mobile access gateway sends a proxy binding update message to the local mobility anchor regarding the current location of the mobile node. Then the LMA sends the proxy binding acknowledgement message, including the home network prefixes, to the MAG.

Now, the mobile access gateway sends a router advertisement on the access link of the mobile node. After receiving the router advertisement messages, the mobile node configures its interface using either state-full or stateless address configuration mechanisms. After address configuration, the mobile node will be having one or more home network prefixes at the current point of attachment to the MAG. The MAG and LMA also will be able to route the traffic through the bidirectional tunnel created as explained above. The signaling flow diagram of PMIPv6 during 
handover interruption time is explained in Fig. 5. The total handover delay $\mathrm{D}^{\mathrm{PMIPv} 6}{ }_{\text {HO}}$, number of hops $\mathrm{N}_{\text {HO }}^{\mathrm{PMIPv6}}$, and average hop delay [Avg Hop Delay] ${ }_{\text {HO }}^{\mathrm{PMIPv6}}$ of PMIPv6 are given below.

$$
\begin{aligned}
& D_{H O}^{P M I P v 6}=t_{r a}+T_{B U}^{P M I P v 6}+\left(t_{m r}+t_{r a}\right) \\
& T_{B U}^{P M I P v 6}=2 \times t_{a m} \\
& N_{H O}^{P M I P v 6}=N_{A P-M A G}^{P M I P v 6}+2 \times N_{M A G-L M A}^{P M I P v 6}+N_{M A G-M N}^{P M I P v 6} \\
& {[A v g \text { Hop Delay }]_{H O}^{P M I P v 6}=\frac{D_{H O}^{P M I P v 6}}{N_{H O}^{P M I P v 6}}}
\end{aligned}
$$

\subsection{FPMIPv6}

Fast handovers are introduced for proxy MobileIP [18] to minimize the handover delay, and packet loss as well as to transfer the network-resident context for a PMIPv6 handover. If the MAGs will be informed about the mobile node's movement before handover, it will be possible to reduce the handover latency and packet loss. In order to further improve the performance during the handover, a bidirectional tunnel between the previous MAG and the new MAG will be established. As mobile nodes are not directly involved in IP mobility management, the Router solicitation for Proxy Advertisement (RtSolPr), the Proxy Router Advertisement (PrRtAdv), Fast Binding Update (FBU), Fast Binding Acknowledgment (FBack), and the Unsolicited Neighbor Advertisement (UNA) messages are not applicable in the PMIPv6 context. Based on the tunneling procedure, there are two modes of operations: Predictive and Reactive. The signalling flow during the handover interruption time of FPMIPv6 for predictive and reactive modes of operation is explained in Fig. 6 and Fig. 7, respectively.

\subsubsection{Predictive FPMIPv6 (FPMIPv6 (Pre))}

In the predictive mode of fast handover, a tunnel is established before attachment to the new mobile access gateway (NMAG). In order to reduce the packet loss during a mobile node's handover, the down-link packets for the mobile node need to be buffered either at the previous mobile access gateway (PMAG) or NMAG. So, all the MAGs should have the capability and enough resources to buffer packets for the mobile node. It is also required that mobile nodes are capable of reporting lower-layer information to the access network (AN) at a short enough interval, and that the AN is capable of sending the handover indication to the PMAG at an appropriate time. The total handover delay $\mathrm{D}^{\mathrm{FPMIPv6(Pre)}}{ }_{\mathrm{HO}}$, number of hops $\mathrm{N}^{\mathrm{FPMIPv6}(\mathrm{Pre})}{ }_{\mathrm{HO}}$, and average hop delay [Avg Hop Delay ${ }^{\mathrm{FPMIPv6}(\mathrm{Pre})}{ }_{\mathrm{HO}}$ of FPMIPv6(Pre) are given below. 


$$
\begin{aligned}
& D_{H O}^{F P M I P v 6(\operatorname{Pr} e)}=2 \times\left(t_{m r}+t_{r a}\right) \\
& N_{H O}^{F P M I P v 6(\operatorname{Pr} e)}=2 \times N_{M N-M A G}^{F P M I P v 6(\operatorname{Pr} e)}
\end{aligned}
$$

$$
[A v g \text { Hop Delay }]_{H O}^{F P M I P v 6(\operatorname{Pr} e)}=\frac{D_{H O}^{F P M I P v 6(\operatorname{Pr} e)}}{N_{H O}^{F P M I P v 6(\operatorname{Pr} e)}}
$$

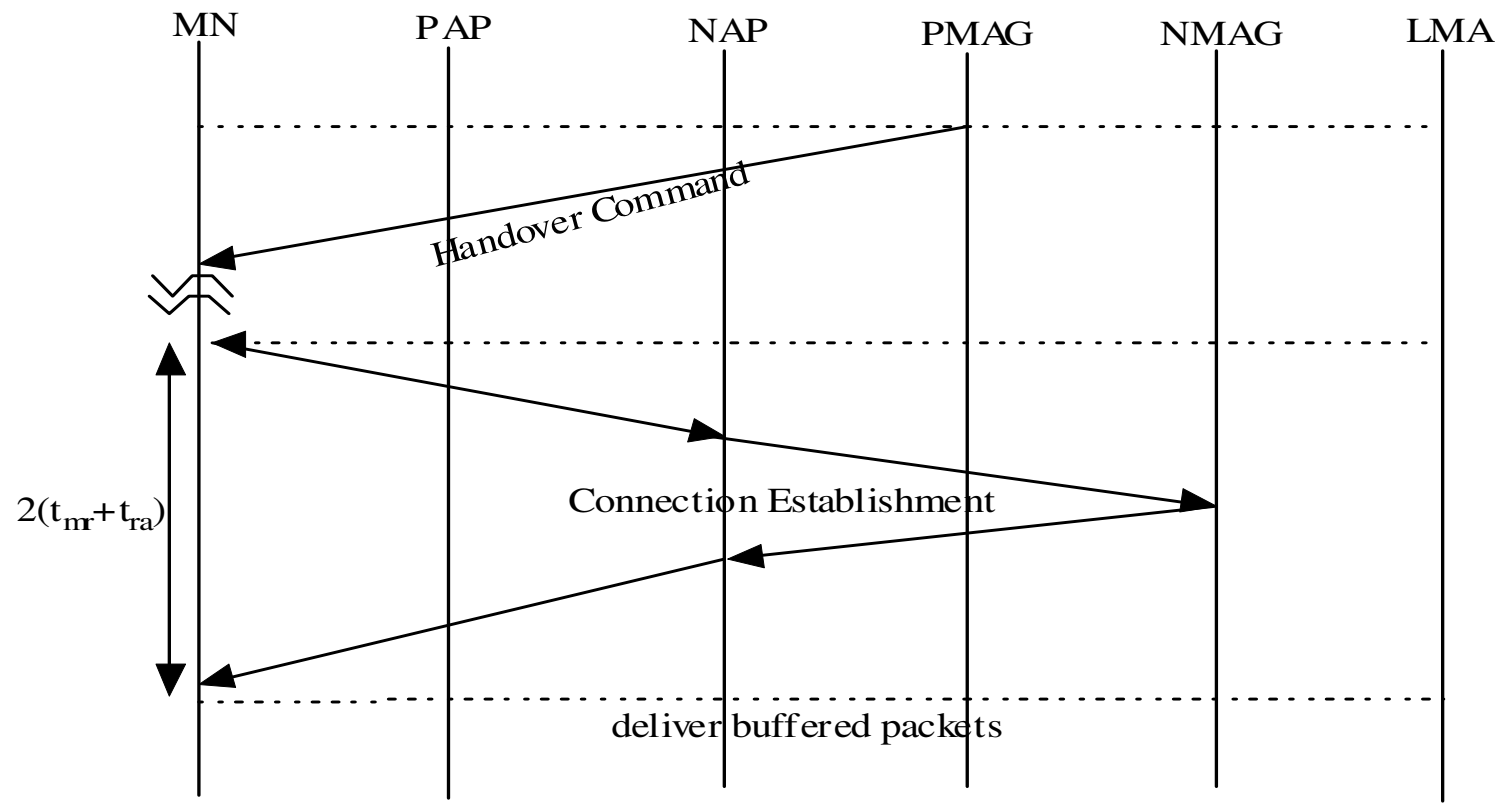

Figure 6. FPMIPv6 (Predictive)

\subsubsection{Reactive FPMIPv6 (FPMIPv6 (Rea))}

In this mode of operation, the tunnel between the previous MAG and new MAG is established after the mobile node attaches to the new MAG. The mobile node does not send either the FBU or UNA, the new MAG sends the handover initiate (HI) message to the previous MAG after the mobile node has moved to the new link. So, the new MAG needs to obtain the information of the previous MAG before establishing the tunnel. Such information can be obtained by the mobile node sending the AP identity on the old link and/or by the lower-layer procedures between the previous access network and the new access network. The total handover delay $\mathrm{D}^{\mathrm{FPMIPv6(Rea)}}{ }_{\mathrm{HO}}$,

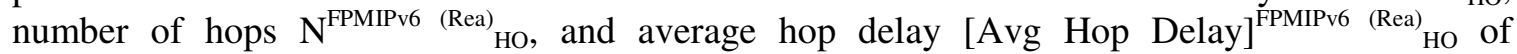
FPMIPv6(Rea) can be expresses as follows: 


$$
\begin{aligned}
D_{H O}^{F P M I P v 6(\operatorname{Re} a)}= & 2 \times\left(t_{m r}+t_{r a}+t_{p n}\right) \\
N_{H O}^{F P M I P v 6(\operatorname{Re} a)}= & 2 \times N_{M N-M A G}^{F P M I P v 6(\operatorname{Re} a)}+N_{N M A G-P M A G}^{F P M I P v 6(\operatorname{Re} a)} \\
& +N_{P M A G-N M A G}^{F P M I P v 6(\operatorname{Re} a)}
\end{aligned}
$$

$[\text { Avg Hop Delay }]_{H O}^{F P M I P v 6(\operatorname{Re} a)}=\frac{D_{H O}^{F P M I P v 6(\operatorname{Re} a)}}{N_{H O}^{F P M I P v 6(\operatorname{Re} a)}}$

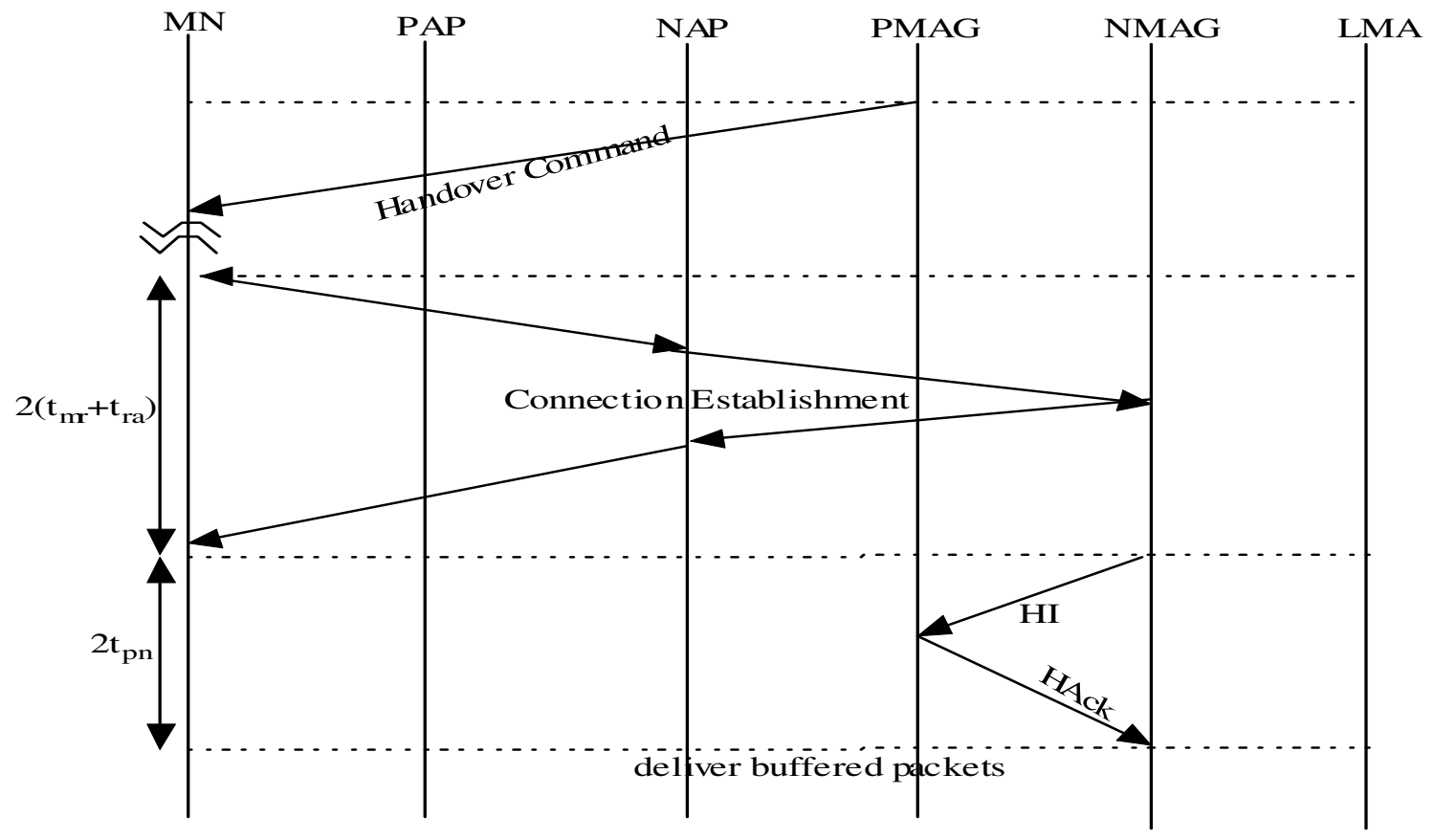

Figure 7. FPMIPv6 (Reactive)

\section{NUMERICAL ANALYSIS}

This section compiles results of numerical analysis of various mobility management protocols under the assumptions presented in Table 3 [6] regarding the protocol operation delay and number of hops involved. By substituting the assumed values of Table 3 for a fixed delay values including wireless link delay, wired part delay components, and binding update/registration latency, and also assuming $\mathrm{N}_{\mathrm{AC}}$ to be 10 hops, the average hop delay of each mobility management protocol is calculated in Table 4. 
Table 3. Assumptions

\begin{tabular}{|l|l|}
\hline Number of hops & Delay \\
\hline $\mathrm{MN}-\mathrm{AR}=2$ & $\mathrm{tmr}=10 \mathrm{~ms}$ \\
\hline $\mathrm{MN}-\mathrm{HA}=4$ & $\mathrm{tra}=2 \mathrm{~ms}$ \\
\hline $\mathrm{MN}-\mathrm{CN}=6$ & $\mathrm{tam}=20 \mathrm{~ms}$ \\
\hline AR-AR $=$ MAG-MAG $=1$ & $\mathrm{thc}=20 \mathrm{~ms}$ \\
\hline $\mathrm{MN}-\mathrm{MAP}=2$ to 4 & $\mathrm{tah}=\mathrm{tac}=40 \mathrm{~ms}$ \\
\hline AP-MAG $=1$ & tpn $=5 \mathrm{~ms}$ \\
\hline MAG-LMA $=1$ & TACMIPv6 $=1000 \mathrm{~ms}$ \\
\hline MN-MAG $=$ MAG-MN=2 & TACHMIPv6 $=1000 \mathrm{~ms}$ \\
\hline
\end{tabular}

Table 4. Average Hop Delay

\begin{tabular}{|l|l|}
\hline Protocol & Average hop delay \\
\hline MIPv6 & $28.042 \mathrm{~ms}$ \\
\hline FMIPv6(Pre) & $5.67 \mathrm{~ms}$ \\
\hline FMIPv6(Rea) & $5.5 \mathrm{~ms}$ \\
\hline HMIPv6 & $49.9 \mathrm{~ms}$ \\
\hline PMIPv6 & $10.8 \mathrm{~ms}$ \\
\hline FPMIPv6(Pre) & $6 \mathrm{~ms}$ \\
\hline FPMIPv6(Rea) & $5.67 \mathrm{~ms}$ \\
\hline
\end{tabular}

As handover latency increases the delay contributed by each hop increases which may degrade the performance of real time applications, and hence it is important to study the effect of average hop delay. In any mobility management protocols, there are two important attributes need to be considered to evaluate the handover performance. These are total handover latency and number of hops taken due to the particular protocol operations. In this regard, there should be a proper relation between total handover latency and number of hops due to a specific protocol. The average hop delay is defined as the ratio between total handover delay and the total number of hops taken due to a particular protocol, and hence the average hop delay is directly proportional to total handover delay and inversely proportional to the total number of hops involved in a particular protocol operation. So it important to study the performance due to these attributes for evaluating mobility management protocols. The total handover delay is a combined effect of various delay components, such as wireless link delay, wired part delay, and binding update/registration delay. This wired part delay again a combination of various delay components, such as movement detection, address configuration, return routability, and neighbor solicitation. In this regard, various MIPv6 protocols have been developed to improve the performance of mobility management by optimizing the different protocol operations. So in this section, we will study the average hop delay performance in terms of these delays components. 


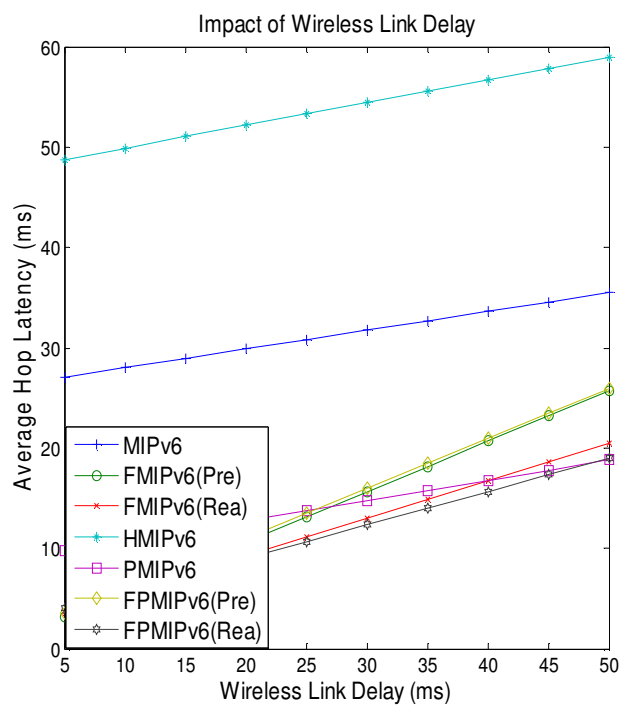

(a)

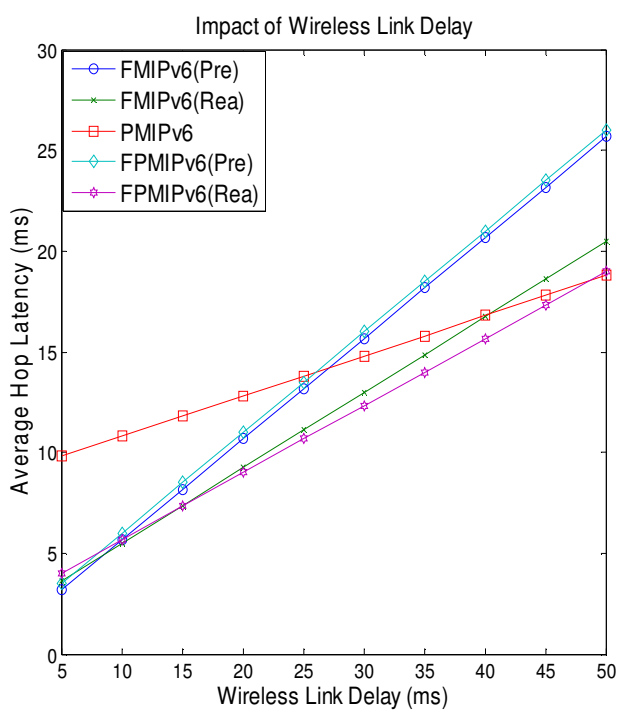

(b)

Figure 8. Average Hop Latency (msec) to Wireless Link Delay (msec) in comparison with MIPv6, FMIPv6 (Predictive), FMIPv6 (Reactive), HMIPv6, PMIPv6, FPMIPv6 (Predictive), FPMIPv6 (Reactive). (a) Normal (b) Expanded version by excluding MIPv6 and HMIPv6.

In this study, we observed the effect of average hop delay in terms of wireless link delay while keeping the delay in the wired part constant. From Fig. 8 it is observed that as the wireless link delay increases, the average hop delay increases for all the protocols. Average hop delay of MIPv6 and HMIPv6 are found as large compared to other protocols, which is mainly because of their more radio access involvement. Even though PMIPv6 protocol performs better than MIPv6 and HMIPv6, PMIPv6 still has a lower performance than FMIPv6 or FPMIPv6. PMIPv6 gives good performance for slower radio access technologies compared to faster radio access technologies (wireless link delay for fast RAT is less than 25ms). Average hop delay of FMIPv6 (Rea) and FPMIPv6 (Rea) are similar, though better while compared to other protocols; on the other hand; FMIPv6 (Pre) and FPMIPv6 (Pre) have similar, though moderate performance. Since, these faster mobility management protocols involve less radio access involvement than other protocols. In comparison with reactive protocols, the predictive protocols are better for very faster radio access technologies (wireless link delay for very fast RAT is less than 10ms). Whereas, for slower radio access technologies reactive protocols are better compared to their predictive counterparts. 


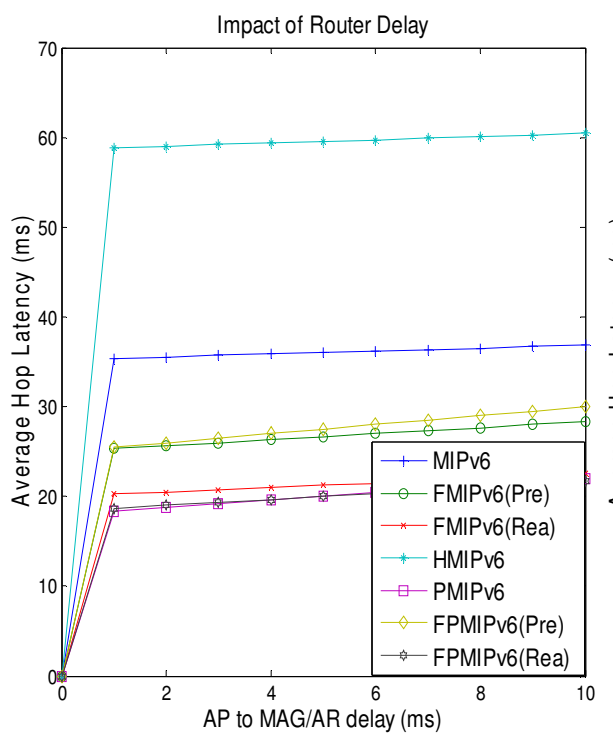

(a)

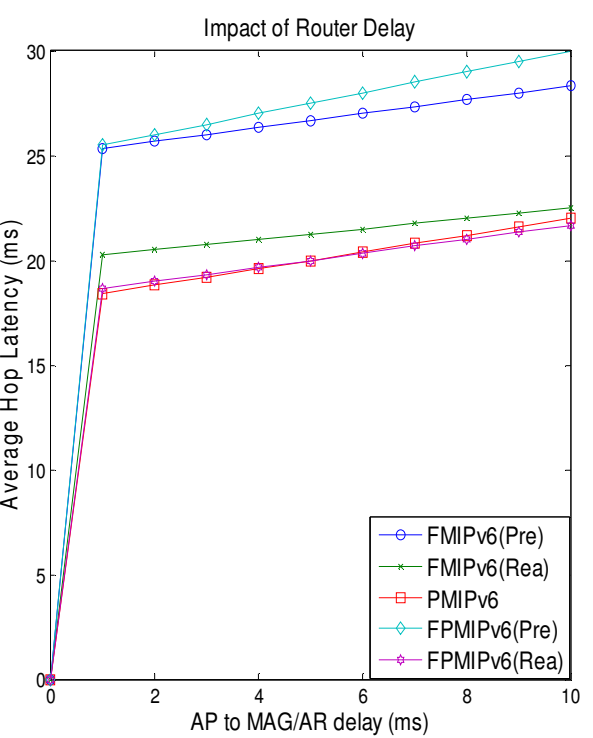

(b)

Figure 9. Average Hop Latency (msec) to Wired Part (AP to MAG/AR) Latency (msec) in comparison with MIPv6, FMIPv6 (Predictive), FMIPv6 (Reactive), HMIPv6, PMIPv6, FPMIPv6 (Predictive), FPMIPv6 (Reactive). (a) Normal (b) Expanded version by excluding MIPv6 and HMIPv6.

The wired part delay between AP and MAG/AR is significant when compared to other delay components in the wired domain. In host based mobility management protocols like MIPv6, FMIPv6, and HMIPv6, this delay is between AP and AR. Whereas in network based protocols like PMIPv6 and FPMIPv6, this delay is between AP and MAG. This delay between AP and MAG/AR entirely depends on protocol operation. The protocols to be developed should consider this delay into account to design the most efficient protocols. So the study of AP to MAG/AR delay is useful to the protocol design. From the Fig. 9, it is observed that as the delay between AP and MAG/AR increases, the average hop delay maintains nearly a steady value, but it is different for different kind of protocols. HMIPv6 and MIPv6 gives more delay compared to other protocols whereas FMIPv6 (Rea), PMIPv6, and FPMIPv6 (Rea) protocols give less average hop delay.

In MIPv6 the delay between AP and AR is due to the following components: movement detection, return routability, and binding update. In each of these operations the mobile node needs to contact the access router to process the protocol operations. Whereas in HMIPv6 movement detection and binding update processes contribute to the delay between AP and AR. Even though the number of protocol operations involved in HMIPv6 is less compared to MIPv6, due to the less number of hops involved in HMIPv6 the average hop delay is less compared to MIPv6, which means that the effect of AP to AR delay is more important in HMIPv6 than MIPv6. The delay between the AP and MAG/AR is almost nearly same in FMIPv6 (Rea), PMIPv6, and PMIPv6 (Rea) protocols and this delay is less compared to other protocols. The average hop delay involved in these protocols is less compared to others due to the fast binding mechanism involved. Similarly FMIPv6 (Pre) and FPMIPv6 (Pre) performs nearly the same performance. The average hop delay in these protocols is moderate compared to other protocols. Even though, the contributing delay component of AP to MAG/AR is same in FMIPv6, and FPMIPv6 for both predictive and reactive mode of operations, the average hop delay in Reactive 
mode of operations is less compared to the predictive mode of operations due to the less number of hops involved in reactive mode of operation.

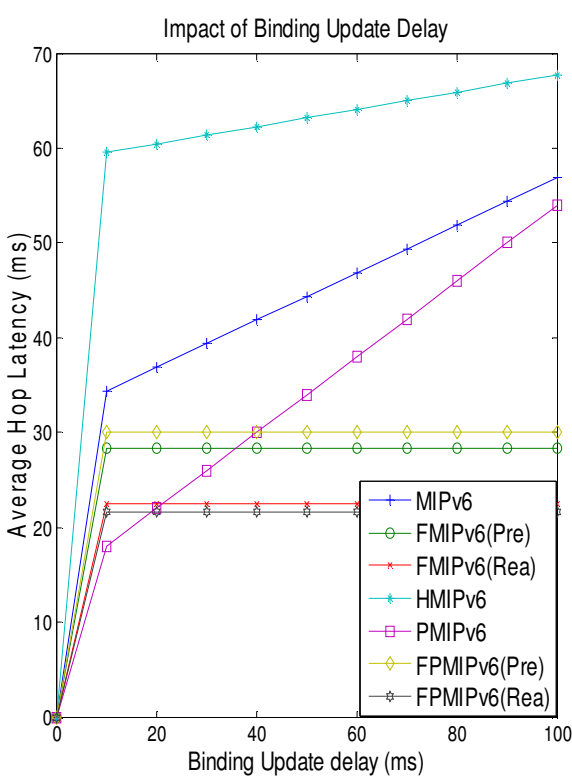

(a)

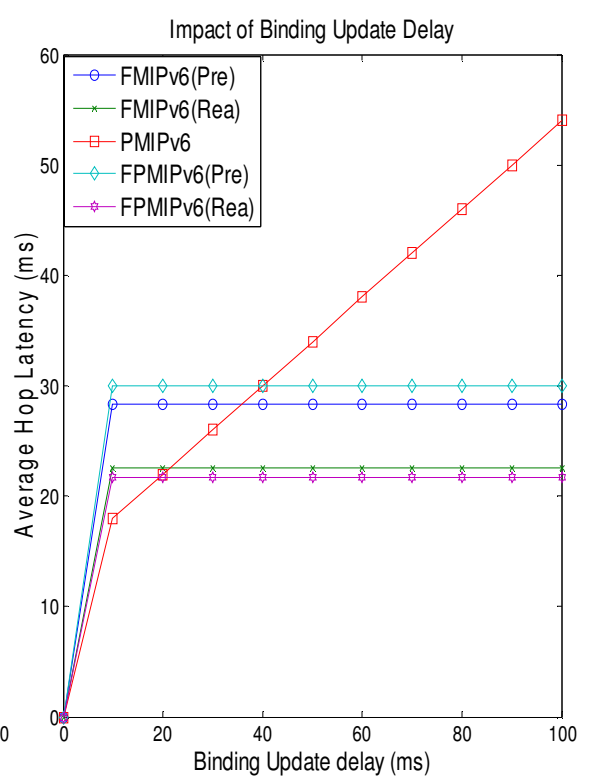

(b)

Figure 10. Average Hop Latency (msec) to Binding Update/Registration Latency $(\mathrm{msec})$ in comparison with MIPv6, FMIPv6 (Predictive), FMIPv6 (Reactive), HMIPv6, PMIPv6, FPMIPv6 (Predictive), FPMIPv6 (Reactive). (a) Normal (b) Expanded version by excluding MIPv6 and HMIPv6.

As the mobile node is moving, maintaining the information about the mobile node is important in mobility management operations, which is done through the binding update and registration operations. The delay involved due to these operations significantly contributes to the total handover delay. From the Fig. 10, it is observed that, as the binding update/ registration latency increases, the average hop delay increases for MIPv6, HMIPv6, and PMIPv6 whereas for FMIPv6 and FPMIPv6 protocols the average hop delay maintains a steady values. This is due to the more binding update and registration operations involved in MIPv6, HMIPv6, and PMIPv6 protocols. Whereas for FMIPv6 and FPMIPv6 protocols, because of fast binding update and registrations, the average hop delay maintains a steady values. Even though the binding update latency is less in HMIPv6, the average hop delay for HMIPv6 is more compared to the MIPv6 due to the less number of hops involved which means that the effect of binding update or registration is more significant in HMIPv6 compared to MIPv6.

Even though the average hop latency in MIPv6 and HMIPv6 is more compared to PMIPv6, the rate of increase in HMIPv6 and MIPv6 is less compared to PMIPv6. The rate of increase in PMIPv6 is mainly because of more delay involved between AP and MAG. From this we can interpret that for faster radio access technologies PMIPv6 provides better performance in terms of average hop delay compared to the slower radio access technologies. The average hop delay of FMIPv6 (Rea) and FPMIPv6 (Rea) is almost nearly the same due to the similar kind of protocol operations involved. The average hop delay of these protocols is less compared to other protocols. The average hop delay of FMIPv6 (Pre) and FPMIPv6 (Pre) protocols perform nearly the same 
performance due to their similar kind of protocol operations. Even though the total handover delay is less for predictive mode of protocols, reactive mode of protocols perform less average hop delay due to the less number of hops involved in these protocols.

From the above interpretation it is observed that for any mobility management protocol design, it is important to study the effect of protocol operations and their delay components. From this analysis we observed that faster network, and faster host based mobility management protocols perform the better average hop delay performance in terms of wireless link delay, wired part delay, and binding update/registration delay. Among these protocols , reactive mode of protocols perform better delay performance in terms of wired part delay and binding update/registration delay components compared to the predictive based protocols. Whereas predictive based protocols performs better performance in terms wireless link delay for faster radio access technologies and performs less performance for slower radio access technologies. One of the important delay components in MIPv6 and HMIPv6 is the delay due to the neighbor solicitation protocol operation which is typically in the order of $1 \mathrm{sec}$. As this delay is not involved in all the mobility management protocols, this study did not consider the effect of this delay component. Even though various faster mobility management protocols have been proposed in the literature, for the seamless mobility operation, it is still important to produce efficient mobility management protocols for achieving the delay upto at most the wireless link delay. In future work we will propose the faster seamless mobility management protocols during vertical handover in heterogeneous wireless networks.

\section{Conclusions}

In this paper, comparative study of various mobility management protocols such as MIPv6, HMIPv6, FMIPv6 (Pre), FMIPv6 (Rea), PMIPv6, FPMIPv6 (Pre), and FPMIPv6 (Rea) is done. The study is carried out to evaluate the performance of these protocols in terms of average hop delay, wireless link delay, delay between AP and MAG/AR, and binding update/registration delay. In this work, the average hop delay is estimated as the ratio of total handover latency to total number of hops taken for each protocol. The analytical results enable us to make the following important observations: for both faster host based and faster network based MIPv6 protocols, the average hop delay performance in terms of wireless link delay, AP to MAG/AR delay, and binding update/registration delay. Among these protocols, reactive mode of protocols perform better delay performance in terms of AP to MAG/AR delay, and binding update/registration delay components while comparing to the predictive based protocols. Whereas predictive based protocols performs better performance in terms wireless link delay for faster radio access technologies and performs less performance for slower radio access technologies. Moreover the study can be extended to consider various other performance metrics such as packet loss, other wired part delay components.

\section{ACKNOWLEDGEMENTS}

This work was carried out under the Vodafone Essar sponsored research project on Wireless Internet at IIT Kharagpur, India. 


\section{REFERENCES}

[1] A. Diab and A. Mitschele-Thiel, "Comparative analysis of proxy mipv6 and fast mipv6", In Proceedings of the 7th ACM international symposium on Mobility management and wireless access, MobiWAC '09, pages 26-33, New York, NY, USA, 2009. ACM.

[2] A. Diab, A. Mitschele-Thiel, K. Getov, and O. Blume, "Analysis of proxy mipv6 performance compared to fast mipv6”, In Local Computer Networks, 2008, 33rd IEEE Conference on, pages 579 -580 , Oct. 2008.

[3] K. D. V. W. K. C. K. Gundavelli, S. Leung and B. Patil, "Proxy mobile ipv6", RFC 5213, August 2008.

[4] C. Johnson, D. Perkins and J. Arkko, "Mobility support in ipv6", RFC 3775, June 2004.

[5] B. Kim, J. Yang, and I. You, “A survey of netlmm in all-ip-based wireless networks”, In Proceedings of the International Conference on Mobile Technology,Applications, and Systems, Mobility '08, pages 60:1-60:6, New York, NY, USA, 2008. ACM.

[6] K.-S. Kong, W. Lee, Y.-H. Han, and M.-K. Shin, "Handover latency analysis of a network-based localized mobility management protocol”, In Communications, 2008. ICC '08. IEEE International Conference on, pages 5838-5843, May 2008.

[7] R. Koodli, "Fast handovers for mobile ipv6", RFC 4068, July 2005.

[8] R. Li, J. Li, K. Wu, Y. Xiao, and J. Xie, "An enhanced fast handover with low latency for mobile ipv6”, Wireless Communications, IEEE Transactions on, 7(1):334 -342, Jan. 2008.

[9] C. Makaya and S. Pierre, "An analytical framework for performance evaluation of ipv6-based mobility management protocols”, Wireless Communications, IEEE Transactions on, 7(3):972 -983, March 2008.

[10] S. W. Moon and J. H. Lee, "Reducing handover delay in mobile ipv6 by cooperating with layer 2 and layer 3 handovers", In Advanced Communication Technology, 2008. ICACT 2008, 10th International Conference on, volume 2, pages 1238 -1241, Feb. 2008.

[11] N. Neumann, J. Lei, X. Fu, and G. Zhang, "I-pmip: an inter-domain mobility extension for proxymobile ip", In Proceedings of the 2009 International Conference on Wireless Communications and Mobile Computing: Connecting the World Wirelessly, IWCMC '09, pages 994-999, New York, NY, USA, 2009. ACM.

[12] B. Obele, J.-K. Rhee, and M. Kang, "A proposal for reducing handover latency and improving route optimization in proxy mobile ipv6", In Advanced Communication Technology, 2008, ICACT 2008. 10th International Conference on, volume 1, pages 49 -54, feb. 2008.

[13] S. Ryu, G.-Y. Kim, B. Kim, and Y. Mun, "A scheme to reduce packet loss during pmipv6 handover considering authentication”, In Computational Sciences and Its Applications, 2008. ICCSA '08. International Conference on, pages 47 -51, 30 2008-July 32008.

[14] C. E. K. Soliman, H. Castelluccia and L. Bellier, "Hierarchical mobile ipv6 mobility management (hmipv6)", RFC 4140, Augest 2005.

[15] M. Uddin, A.-S. Pathan, S. Haseeb, and M. Ahmed, "A test-bed analysis for seamless mipv6 handover in heterogeneous environment”, In Consumer Electronics (ISCE), 2011 IEEE 15th International Symposium on, pages 89 -94, June 2011.

[16] Y. Wang, Y. Feng, and L. Zhang, "Coordinating fast handover and route optimization in proxy mobile ipv6", In Wireless Communications, Networking and Mobile Computing, 200, WiCom '09, 5th International Conference on, pages $1-4$, Sept. 2009.

[17] B. K. J. G. S. Xia, F. Sarikaya and D. Damic, "RADIUS Support for Proxy Mobile IPv6", InternetDraft draft-ietf-netext-radius-pmip6-06, Internet Engineering Task Force, 2012.Work in progress.

[18] K. K. R. P. B. Yokota, H. Chowdhury and F. Xia, "Fast handovers for proxy mobile ipv6", RFC 5949, September 2010. 


\section{AUTHORS}

$\mathrm{K}$ Vasu is a Ph.D student at Department of Electronics and Electrical Communication Engineering at Indian Institute Technology Kharagpur, India. He has received his masters in Advance Networking from ABV-Indian Institute of Information Technology, Gwalior, India in 2008. His current research area is Vertical Handover in Heterogeneous Wireless Networks and Mobility Management Protocols for Next Generation Networks.

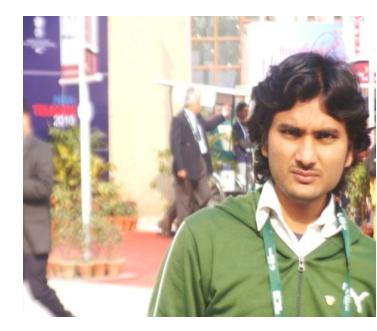

Sudipta Mahapatra graduated in Electronics and Telecommunication Engineering from Sambalpur University, Orissa, India in the year 1990. He obtained his M.Tech and $\mathrm{Ph}$. D degrees in Computer Engineering from IIT, Kharagpur in the year 1992 and 1997 respectively. From April 1993 to September 2002 he wa s working in the Computer Science and Engineering department of National Institute of Technology, Rourkela. He was in the Electronic Systems Design Group of Loughborough University, UK, as a BOYSCAST Fellow of DST, Government of India, from March 1999 to March

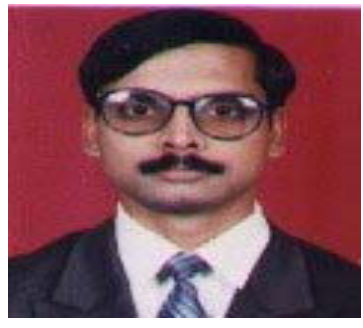
2000. He joined the E \& ECE Department of IIT Kharagpur in Sept. 2002 where currently he is working as an Associate Professor. His areas of research interests include: image and video coding/compression and optical/wireless networking.

Prof C.S.Kumar received his B. Tech degree from IIT Kharagpur, West Bengal, India in 1987 and Ph.D degree from Indian Institute of Technology, Kharagpur, India in 1995.He did his P.Doc at Electro Technical Laboratory Tsukuba, Japan in 1999. Dr. Kumar is working as a Associate Professor in the Dept. of Mechanical Engineering, IIT. Kharagpur. His research activities are in ROBOTICS, INTELLIGENT SYSTEMS, COMPUTER NETWORKS, HUMAN COMPUTER INTERACTIONS.

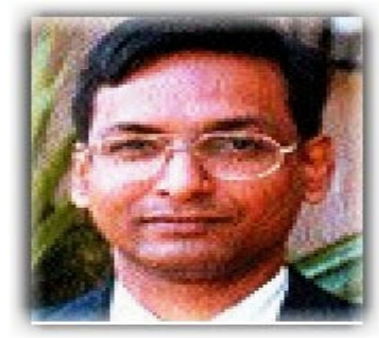

